\title{
Modeling and optimization of small-scale NF/RO seawater desalination using the artificial neural network (ANN)
}

\author{
Asma Adda ${ }^{1,2^{\dagger}}$, Salah Hanini ${ }^{1}$, Salah Bezari ${ }^{2}$, Maamar Laidi ${ }^{1}$, Mohamed Abbas ${ }^{3}$ \\ ${ }^{1}$ Laboratory of Biomaterials and Transport Phenomena (LBMPT), Faculty of Science and Technology, university of Dr Yahia fares Medea, Algeria \\ ${ }^{2}$ Unité de Recherche Appliquée en Energies Renouvelables, URAER, Centre de Développement des Energies Renouvelables, CDER, 47133 Ghardaïa, \\ Algeria \\ ${ }^{3}$ Unit of Solar Equipments Development-UDES/EPST CDER, Head of research department: Cooling Systems and Water Treatment using Renewable \\ Energies-FTEER, Tipaza, Algeria
}

\begin{abstract}
The performance of seawater hybrid NF/RO desalination plant including permeate conductivity; permeate flow rate and permeate recovery. Under different feed parameters time, inlet temperature, inlet pressure, inlet conductivity and inlet flow rate were modelled by Artificial Neural Network (ANN) back-propagation based on Levenberg- Marquardt training algorithm. The optimal ANN model had a 5-8-3 architecture with a hyperbolic tangent transfer function in hidden layer and linear transfer function at the output layer. The ability of ANN performed model was compared with multiple linear regression (MLR). The results show that MLR is not satisfactory for predicting the performance of $\mathrm{NF} / \mathrm{RO}$ hybrid desalination process with a correlation coefficient about 0.6. The trained ANN model has presented a good agreement between the prediction and the experimental data during the training with reasonable statistical metrics values (RMSE, MAE and AARD). The coefficient of determination values for the prediction of permeate conductivity, permeate flow rate and recovery by ANN were 0.969 , 0.942, and 0.963, respectively. Therefore, the ANN model can successfully predict the performance of NF/RO hybrid seawater desalination plant.
\end{abstract}

Keywords: Artificial Neural Network (ANN), Conductivity, Flow rate, NF/RO process, Recovery, Seawater desalination

\section{Introduction}

Reverse osmosis (RO) technology is advanced technology for desalination plants. It accounts for $90 \%$ of the total desalination capacity installed worldwide [1, 2]. RO membranes have currently used in a wide range of applications, including brackish / seawater desalination, drinking water treatment and wastewater reuse [3]. The efficiency of RO membranes in various water treatments is often limited due to membrane fouling. However, to reduce or even overcome these limits, several studies have showed that de NF process can be coupled to RO for seawater desalination [4]. Thus, nanofiltration (NF) is a membrane technology that has positioned between $\mathrm{RO}$ and ultrafiltration. NF membranes can reduce the ionic strength of the solution. Moreover, hardness, organics, and particulate contaminants can be removed by $\mathrm{NF}$ membranes [5].
Integrating $\mathrm{NF}$ with $\mathrm{RO}$ desalination process may decrease the complexity and cost of desalination plant. However, NF pretreatment has considered a breakthrough for the desalination process. $\mathrm{NF}$ offers several advantages such as low operating pressure, high flux, high retention of multivalent anion salts and organic matter, relatively low investment and low operation and maintenance costs $[6,7]$ and integrated NF with RO could join the advantages from both kinds of membranes [8, 9].

Several researchers have provided to increase the water recovery of RO systems without reducing the membranes life. The performance of $\mathrm{NF}$ processes cannot meet drinking water standards because of its inability to reduce salinity in seawater [10, 11].

Many works have been carried out using the NF process for pretreatment, although, the NF permeate quality was excellent, nonetheless the NF permeate water recovery ratio was modest about $50 \%$ at an applied pressure of 30 bar [12]. Another advant-
cC) (P) $\$$ This is an Open Access article distributed under the terms of the Creative Commons Attribution Non-Commercial License (http://creativecommons.org/licenses/by-nc/3.0/) which permits unrestricted non-commercial use, distribution, and reproduction in any medium, provided the original work is properly cited.

Copyright (C) 2022 Korean Society of Environmental Engineers
Received July 03, 2020 Accepted March 08, 2021

${ }^{\dagger}$ Corresponding author

E-mail: a.docsolaire2017@gmail.com

Tel: +213774 435070

ORCID: 0000-0003-2487-7563 
age, related to the high performance of desalination systems, can be reducing the price of desalted water. Hassan et al. [13, 14] proposed the NF-RO low-cost seawater desalination process. they show that with low pressure of 22 bar, the $\mathrm{Ca}^{2+}, \mathrm{Mg}^{2+}$, $\mathrm{SO}_{4}^{-2}, \mathrm{HCO}^{3-}$ and total hardness rejection of $\mathrm{NF}$ were $89.4 \%$, $94.0 \%, 97.8 \%, 96.6 \%$ and $93.3 \%$, respectively, and the rejection rate of monovalent ions $\left(\mathrm{Cl}^{-}, \mathrm{Na}^{+}\right)$was $40.3 \%$, achieving about $27 \%$ reduction in the net water production cost through a single-stage SWRO. For the first time, the NF membrane pretreatment process was integrated with one of the conventional desalination processes on a pilot plant in Saudi Arabia. This conception was evaluated on NF-SWRO, NF-MSF, and NF-SWRO-MSF pilot plant units using Gulf seawater [15]. Drioli et al. [16, 17] integrated the MF-NF-RO system with membrane distillation/crystallization (MD/MC) units. To achieve the high water recovery rates of $92.8 \%$. NF is used for pretreatment and load reduction to the following RO unit, a membrane crystallizer completes was used and available waste thermal energy and brine pressure exchanger system. The energy consumption of the NF-RO-MC process was reduced to $1.54-1.61 \mathrm{kWh} / \mathrm{m}^{3}$ and the water cost is reduced to $0.56 \$ / \mathrm{m}^{3}$. In seawater desalination process, NF is applied as a pretreatment step of seawater feed and RO or MSF as final treatment step [18]. AlTaee and Sharif [19] carried out the cost analysis on a dual NF-NF, NF-RO and single RO systems. The results showed that NF-NF combination was the lower cost followed by RO then NF-RO systems. In another study, Kaya et al. [20], for applicability of NF membranes prior to the SWRO system was also investigated. They reported that SWRO flux increased from 30.1 LMH to 55.1 LMH when NF was used as a pretreatment prior to seawater SWRO unit (flux of single SW30-RO membrane was $30.1 \mathrm{LMH}$ at $55 \mathrm{bar}$, while the average flux of the integrated NF90 (30 bar) + SW30-RO (40 bar) system flux was 55.1 LMH). The results showed a good rejection with respect to all ions.

In a recent study, Kaya et al. [21] investigated NF membranes as a pretreatment prior to RO in seawater desalination. The membranes used were NF270 and NF90 as the NF membranes, while the brackish water RO membrane BW30 was used as the RO membrane. The permeate water of the NF membranes was collected and used as the feed to the BW30 membrane.

However, the NF/RO separation process is the most complex operating and control of all major membrane operations [22]. The operating conditions are taken into consideration when modelling a $\mathrm{RO} / \mathrm{NF}$ membrane system. There are certain factors, which greatly affect the performance of a NF/RO hybrid system. However, the parameters that significantly affects the performance of NF/RO desalination plant are the permeate water quality (conductivity, $\mathrm{pH}$ ), permeate flow rate, the permeate recovery, the permeability and rejection.

Traditionally, membrane performance has been predicted by polynomial correlations, but the neural network model offers the advantage allowing the user to visualise the entire operation, the capability of learning from the experimental results and obtaining highly accurate findings.

In recent years, the application of ANN for modelling has been greatly increased success in various fields of engineering sciences. Among the methods of linear regression and correlation multivariable widely studied in the 70th, the neural approach allowed the establishment of a model from non-linear relations between inputs and outputs of the process [23].

The use of ANN in the field of desalination with RO technology, it should be noted that since 1993. When El-Hawary [24] proposed some possible applications of ANNs in desalination proposals have been published for the use of ANNs in tasks including optimization the operation of the SWRO desalination plant. Abbas et al. [25] identified the variable of permeate flow rate to be controlled in RO seawater and brackish plant with ANN. Garg et al. [26] used ANN simulation to study the performance of small-scale RO membrane which control the permeate recovery, the TDS and specific energy consumption. Aish et al. [27] considered the permeate flow rate and TDS adequate variables to control and modeling of five large and small scale brackish water plants in Gaza strip.

Madaeni et al. [28] applied the ANN model to predict the permeate flow rate, conductivity which optimize and control of RO water treatment. Recently, Cabrera et al. [29] considered the application of an ANN control system of an RO seawater desalination unit, which predict the pressure, feed flow rate, and permeate flow rate, conductivity.

This paper presents the experimental results obtained from a small scale NF/RO hybrid system conducted by Hamed [30] and developed a method for the simulation of membrane performance by using artificial neural networks. The neural network model successfully predicts the three important parameters on which the $\mathrm{NF} / \mathrm{RO}$ operation is based i.e. the permeate conductivity, permeate flow rate and permeate recovery.

The aim of this study was to investigate the capacity of an ANN to modeling the performance of $\mathrm{NF} / \mathrm{RO}$ seawater desalination plant by means of prediction the permeate conductivity, permeate flow rate and permeate recovery. The performance of the ANN models was compared to MLR.

\section{Material and Method}

\subsection{Experimental Data}

The Saline Water Desalination Research Institute (SWRI) [30] provided the experimental NF/SWRO desalination plant data used for building the ANN model. A pilot plant testing in which the NF membrane NF product is sent to the $\mathrm{RO}$ unit and its brine reject is used as a make-up to the MSF plant, the NF unit received pretreated seawater with a temperature feed varies between $24^{\circ} \mathrm{C}$ and $34^{\circ} \mathrm{C}$ and was operated with operating pressure about $24 \mathrm{~kg} / \mathrm{cm}^{2}$ at a recovery of $53-57 \%$. The SWRO unit that received the NF product as feed the operating pressure was maintained at 60 $\mathrm{kg} / \mathrm{cm}^{2}$ and a temperature ranged from 23 to $34^{\circ} \mathrm{C}$, where the average permeate recovery of the first and second vessels were 30 and $21 \%$, respectively but the overall recovery the SWRO system was about $45 \%$. Fig. 1 shows the diagram of the trihybrid $\mathrm{NF} / \mathrm{RO} / \mathrm{MSF}$ desalination pilot system. The samples of water were collected every hour for a period of two months, the selected parameters including: the feed pressure, temperature, conductivity, flow rate, permeate flow rate and permeate water recovery. The selected experimental inputs and outputs variation presented in Table 1. 
Table 1. Input and the Output Experimental Parameters Extracted with Getdata, Graph, Digitizer Software [30]

\begin{tabular}{|c|c|c|c|c|c|c|c|c|}
\hline & $\begin{array}{c}\text { Time } \\
\text { (h) }\end{array}$ & $\begin{array}{l}\text { Pressure } \\
\left(\mathrm{kg} / \mathrm{cm}^{2}\right)\end{array}$ & $\begin{array}{c}\text { Temperature } \\
\left({ }^{\circ} \mathrm{C}\right)\end{array}$ & $\begin{array}{l}\text { Flow feed } \\
\left(\mathbf{m}^{3} / \mathbf{h}\right)\end{array}$ & $\begin{array}{l}\text { Conductivity feed } \\
\qquad(\mu \mathrm{S} / \mathrm{cm})\end{array}$ & $\begin{array}{c}\text { Permeate recovery } \\
\text { (\%) }\end{array}$ & $\begin{array}{l}\text { Permeate flow } \\
\qquad\left(\mathrm{m}^{3} / \mathrm{h}\right)\end{array}$ & $\begin{array}{l}\text { rate Permeate conductivity } \\
\qquad(\mu \mathrm{S} / \mathrm{cm})\end{array}$ \\
\hline 1 & 25.197 & 24.036 & 25.852 & 7.817 & $60,170.213$ & 41.579 & 1.317 & $1,117.257$ \\
\hline 2 & 37.795 & 24.3049 & 25.9193 & 8.1667 & $60,777.3$ & 41.0931 & 1.30732 & $1,128.32$ \\
\hline 3 & 48.294 & 24.507 & 25.987 & 8.014 & $61,021.277$ & 41.255 & 1.288 & $1,128.319$ \\
\hline 4 & 71.391 & 24.036 & 25.785 & 7.971 & $61,234.043$ & 41.093 & 1.288 & $1,117.257$ \\
\hline 5 & 83.9895 & 24.0359 & 25.852 & 8.2363 & $61,021.3$ & 40.9312 & 1.2873 & 1,139.38 \\
\hline 6 & 94.588 & 23.901 & 26.323 & 7.929 & $60,382.979$ & 41.255 & 1.298 & $1,139.381$ \\
\hline 7 & 121.785 & 23.901 & 25.785 & 7.886 & $60,382.979$ & 44.494 & 1.385 & $1,084.071$ \\
\hline 8 & 132.59 & 23.968 & 25.0448 & 8.0333 & $61,061.6$ & 43.5223 & 1.36585 & $1,073.01$ \\
\hline 9 & 144.882 & 23.901 & 23.969 & 7.628 & $61,553.191$ & 43.360 & 1.346 & $1,073.009$ \\
\hline 10 & 167.979 & 23.767 & 24.103 & 7.671 & $61,765.957$ & 43.360 & 1.366 & $1,106.195$ \\
\hline 11 & 180.577 & 23.834 & 25.718 & 7.757 & $61,766.000$ & 43.522 & 1.376 & $1,117.260$ \\
\hline 12 & 191.076 & 23.901 & 27.063 & 7.800 & $61,659.574$ & 43.684 & 1.376 & $1,139.381$ \\
\hline 13 & 216.273 & 24.507 & 27.534 & 7.800 & $61,234.043$ & 44.008 & 1.385 & $1,139.381$ \\
\hline 14 & 241.470 & 24.440 & 27.466 & 7.843 & $61,127.660$ & 44.818 & 1.424 & $1,139.381$ \\
\hline 15 & 264.567 & 24.440 & 27.265 & 7.800 & $60,702.128$ & 44.980 & 1.463 & $1,095.133$ \\
\hline 16 & 287.664 & 24.440 & 26.928 & 7.671 & $60,808.511$ & 45.951 & 1.424 & $1,106.195$ \\
\hline 17 & 310.761 & 24.036 & 28.005 & 7.800 & $61,765.957$ & 44.170 & 1.385 & $1,172.566$ \\
\hline 18 & 323.36 & 24.1704 & 26.9955 & 7.96667 & $61,725.1$ & 44.332 & 1.3561 & $1,128.32$ \\
\hline 19 & 335.958 & 24.507 & 25.112 & 7.586 & $61,872.340$ & 43.036 & 1.356 & $1,095.133$ \\
\hline 20 & 361.155 & 23.969 & 26.256 & 7.757 & $61,021.277$ & 44.818 & 1.405 & $1,084.071$ \\
\hline 21 & 384.252 & 24.507 & 25.987 & 7.757 & $60,808.511$ & 44.818 & 1.395 & $1,061.947$ \\
\hline 22 & 407.349 & 24.036 & 25.852 & 7.628 & $60,702.128$ & 44.980 & 1.424 & $1,039.823$ \\
\hline 23 & 419.948 & 24.2377 & 25.7848 & 8.02424 & $60,595.7$ & 44.9798 & 1.4218 & $1,039.82$ \\
\hline 24 & 432.546 & 24.440 & 26.188 & 7.714 & $60,489.362$ & 44.656 & 1.415 & $1,050.885$ \\
\hline 25 & 455.643 & 23.901 & 26.659 & 7.671 & $60,489.362$ & 44.656 & 1.385 & $1,061.947$ \\
\hline 26 & 478.740 & 24.036 & 27.130 & 7.714 & $60,382.979$ & 45.304 & 1.434 & $1,084.071$ \\
\hline 27 & 503.937 & 23.969 & 27.466 & 7.757 & $60,382.979$ & 44.818 & 1.415 & $1,128.319$ \\
\hline 28 & 527.034 & 23.969 & 27.466 & 7.757 & $60,276.596$ & 44.170 & 1.366 & $1,150.442$ \\
\hline 29 & 539.633 & 26.659 & 25.987 & 7.757 & $60,276.600$ & 44.332 & 1.376 & $1,139.380$ \\
\hline 30 & 552.231 & 29.484 & 27.870 & 7.757 & $60,382.979$ & 44.494 & 1.376 & $1,150.442$ \\
\hline 31 & 575.328 & 30.493 & 27.466 & 7.800 & $61,127.660$ & 44.494 & 1.385 & $1,205.752$ \\
\hline 32 & 600.525 & 29.955 & 27.534 & 7.714 & $60,382.979$ & 44.008 & 1.366 & $1,139.381$ \\
\hline 33 & 623.622 & 30.493 & 29.148 & 7.800 & $60,276.596$ & 45.304 & 1.444 & $1,250.000$ \\
\hline 34 & 636.22 & 30.2915 & 28.3408 & 8.06667 & 60,019 & 44.332 & 1.43415 & 1,250 \\
\hline 35 & 648.819 & 30.022 & 29.619 & 7.800 & $59,957.447$ & 44.818 & 1.424 & $1,238.938$ \\
\hline 36 & 671.916 & 29.484 & 29.417 & 7.671 & $60,063.830$ & 45.304 & 1.424 & $1,216.814$ \\
\hline 37 & 697.113 & 30.022 & 30.426 & 7.586 & $60,063.830$ & 44.980 & 1.395 & $1,172.566$ \\
\hline 38 & 705.512 & 30.2242 & 29.8206 & 7.9818 & $59,957.4$ & 44.9798 & 1.38104 & $1,194.69$ \\
\hline 39 & 720.210 & 30.493 & 29.888 & 7.671 & $60,063.830$ & 44.494 & 1.376 & $1,205.752$ \\
\hline 40 & 745.407 & 30.426 & 29.955 & 7.714 & $59,851.064$ & 45.466 & 1.424 & $1,194.690$ \\
\hline 41 & 768.504 & 30.426 & 29.955 & 7.757 & $59,851.064$ & 45.628 & 1.434 & $1,095.133$ \\
\hline 42 & 791.601 & 30.493 & 30.493 & 7.714 & $60,063.830$ & 45.142 & 1.405 & $1,194.690$ \\
\hline 43 & 814.698 & 31.502 & 31.166 & 7.628 & $60,063.830$ & 45.951 & 1.483 & $1,216.814$ \\
\hline 44 & 839.895 & 26.996 & 30.022 & 7.800 & $60,276.596$ & 44.656 & 1.444 & $1,227.876$ \\
\hline 45 & 852.493 & 28.2735 & 3.2915 & 8.03333 & $60,208.5$ & 44.9798 & 1.42439 & $1,205.75$ \\
\hline 46 & 854.593 & 28.341 & 29.283 & 7.714 & $60,276.600$ & 44.700 & 1.415 & $1,183.630$ \\
\hline 47 & 865.092 & 29.283 & 28.946 & 7.671 & $60,276.596$ & 44.332 & 1.405 & $1,161.504$ \\
\hline
\end{tabular}


Table 1. Continued

\begin{tabular}{|c|c|c|c|c|c|c|c|c|}
\hline & $\begin{array}{c}\text { Time } \\
\text { (h) }\end{array}$ & $\begin{array}{l}\text { Pressure } \\
\left(\mathrm{kg} / \mathbf{c m}^{2}\right)\end{array}$ & $\begin{array}{c}\text { Temperature } \\
\left({ }^{\circ} \mathrm{C}\right)\end{array}$ & $\begin{array}{c}\text { Flow feed } \\
\left(\mathrm{m}^{3} / \mathbf{h}\right)\end{array}$ & $\begin{array}{l}\text { Conductivity feed } \\
\qquad(\mu \mathrm{S} / \mathrm{cm})\end{array}$ & $\begin{array}{c}\text { Permeate recovery } \\
(\%)\end{array}$ & $\begin{array}{l}\text { Permeate flow rate } \\
\left(\mathrm{m}^{3} / \mathrm{h}\right)\end{array}$ & $\begin{array}{l}\text { Permeate conductivity } \\
\qquad(\mu \mathrm{S} / \mathrm{cm})\end{array}$ \\
\hline 48 & 886.089 & 29.417 & 29.014 & 7.800 & $60,276.596$ & 45.142 & 1.405 & 1,106.195 \\
\hline 49 & 911.286 & 29.484 & 28.206 & 7.800 & $60,276.596$ & 45.142 & 1.454 & $1,073.009$ \\
\hline 50 & 936.483 & 30.022 & 30.022 & 7.757 & $60,063.830$ & 44.818 & 1.454 & $1,161.504$ \\
\hline 51 & 946.982 & 31.839 & 31.839 & 7.800 & $60,063.800$ & 44.817 & 1.446 & $1,139.380$ \\
\hline 52 & 949.081 & 30.0224 & 30.4933 & 8.03333 & 60,019 & 44.0081 & 1.45366 & 1,139.38 \\
\hline 53 & 959.580 & 30.022 & 31.771 & 7.843 & $60,063.830$ & 44.818 & 1.434 & $1,128.319$ \\
\hline 54 & 984.777 & 30.022 & 32.646 & 7.586 & $60,170.213$ & 44.494 & 1.434 & $1,117.257$ \\
\hline 55 & $1,007.870$ & 29.484 & 31.839 & 7.757 & $60,170.213$ & 44.656 & 1.444 & $1,161.504$ \\
\hline 56 & $1,030.970$ & 29.955 & 33.587 & 7.714 & $60,170.213$ & 43.360 & 1.395 & $1,128.319$ \\
\hline 57 & $1,043.57$ & 29.8879 & 32.9821 & 7.9818 & $60,808.5$ & 43.198 & 1.38876 & $1,150.44$ \\
\hline 58 & $1,056.170$ & 29.753 & 28.946 & 7.800 & $61,234.043$ & 43.522 & 1.395 & $1,161.504$ \\
\hline 59 & $1,066.67$ & 29.8879 & 31.9058 & 8.03333 & $61,061.6$ & 44.0081 & 1.42439 & $1,117.26$ \\
\hline 60 & $1,081.360$ & 29.955 & 32.444 & 7.714 & $60,808.511$ & 44.494 & 1.454 & $1,073.009$ \\
\hline 61 & 1,096.06 & 29.8879 & 31.435 & 8 & $60,398.1$ & 44.0081 & 1.4439 & $1,117.26$ \\
\hline 62 & $1,102.360$ & 29.955 & 32.444 & 7.714 & $60,382.979$ & 44.008 & 1.434 & $1,150.442$ \\
\hline 63 & $1,127.560$ & 29.552 & 32.444 & 7.757 & $60,170.213$ & 44.008 & 1.415 & $1,172.566$ \\
\hline 64 & $1,150.660$ & 29.014 & 32.579 & 7.757 & $60,170.213$ & 44.008 & 1.415 & $1,150.442$ \\
\hline 65 & $1,173.750$ & 29.014 & 32.713 & 7.628 & $60,063.830$ & 44.656 & 1.463 & $1,150.442$ \\
\hline 66 & $1,201.050$ & 30.022 & 32.713 & 7.800 & $60,170.213$ & 44.170 & 1.444 & $1,150.442$ \\
\hline 67 & $1,224.150$ & 29.955 & 33.184 & 7.628 & $60,170.213$ & 43.846 & 1.405 & $1,161.504$ \\
\hline 68 & $1,247.240$ & 30.695 & 32.915 & 7.757 & $60,170.213$ & 44.494 & 1.444 & $1,172.566$ \\
\hline 69 & $1,270.340$ & 31.031 & 32.444 & 7.757 & $60,382.979$ & 44.494 & 1.424 & $1,161.504$ \\
\hline 70 & $1,295.540$ & 28.812 & 32.377 & 7.586 & $60,276.596$ & 44.170 & 1.424 & $1,172.566$ \\
\hline 71 & 1,318.640 & 29.821 & 32.780 & 7.800 & $60,276.596$ & 44.332 & 1.434 & $1,161.504$ \\
\hline 72 & $1,331.23$ & 29.417 & 33.2511 & 8.0333 & $60,398.1$ & 44.332 & 1.4315 & $1,205.75$ \\
\hline 73 & $1,343.830$ & 28.812 & 33.789 & 7.843 & $60,382.979$ & 44.170 & 1.434 & $1,238.938$ \\
\hline
\end{tabular}

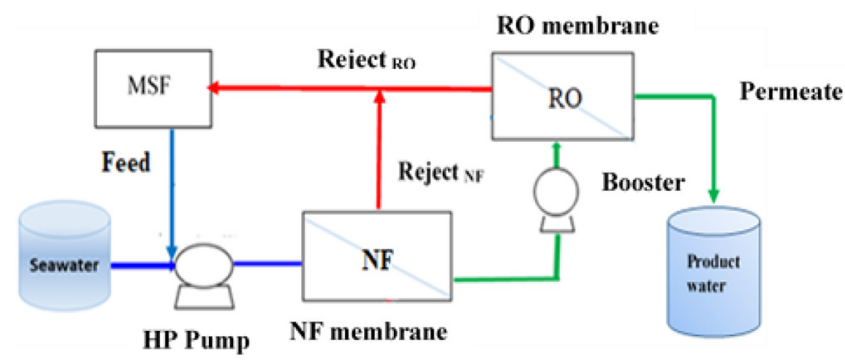

Fig. 1. Hybrid NF/RO seawater desalination pilot plant system.

\subsection{Modeling Development}

Using a method to control a simulated NF/RO seawater desalination unit. Two approaches were used to develop the most adequate model for the prediction of permeate conductivity, permeate flow rate and permeate recovery.

\subsubsection{Neural network modelling}

ANN models were built, to predict permeate conductivity, permeate flow rate and recovery (i.e., target variables) using a back-propagation (BP) based on Levenberg- Marquardt algorithm [31] to establish the relationships between the selected model inputs and the target variables. The information propagates in one direction only the forward direction. Determination of the optimum number of hidden layers and nodes within each layer are real problem, and there is no procedure available to know this for first time. For that, a trial and error approach (multiple runs) was followed to get at the best network architecture [32, 33].

The experimental data used to construct the ANN model for $\mathrm{NF} / \mathrm{RO}$ seawater desalination plant are summarized in Table 1. A total number of 73 different experiments were employed to predict permeate conductivity permeate recovery and permeate flow rate were divided into training and test subsets. As training subset a number of 60 samples, a percentage of $80 \%$ of all available data. For test subset, 13 samples (a percentage of 20\%) have been considered. The split of data into training and test subsets was carried out to estimate the performance of the neural network. The neuronal network-training model was developed by means of a program written in MATLAB software. Fig. 2 presents the schematic diagram of an ANN where 5 input neurons were selected at the input layer, 3 output neuron that had been taken at the output layer. The results show that the optimal fully connected ANN was obtained using 8 neurons in the hidden layer, with high $\mathrm{R}$ and low RMSE. Different ANN structures with two hidden layers and different neurons in each layer have been tested. It 
was notable that the ANN with 02 hidden layers can predict the three outputs accurately.

In this investigation, the tangent sigmoid (tansig) as transfer functions was used in the hidden layer (Eq. (1)) and pure linear (purelin) transfer function in the output layer (Eq. (2)). However, the tansig function, produces output in the range of -1 to +1 and the linear transfer function produce outputs in the range of $-\infty$ to $+\infty[34,35]$

$$
\begin{gathered}
Z(x)=\frac{e^{x}-e^{-x}}{e^{x}+e^{-x}} \\
Z(x)=x
\end{gathered}
$$

Whereas normalization is required when there is a difference in the ranges of the input data. In this work, all the training data was normalized between -1 and 1, using Eq. (3) is expressed in the follow:

$$
x_{\text {norm }}=\frac{2\left(x_{i}-\min \left(x_{\mathrm{i}}\right)\right)}{\max \left(x_{i}\right)-\min \left(x_{i}\right)}-1
$$

Where $x_{i}$ is the input or output variable $x, x_{\max }$ and $x_{\min }$ are equal to the maximum and minimum values noted for each variable of $x$.

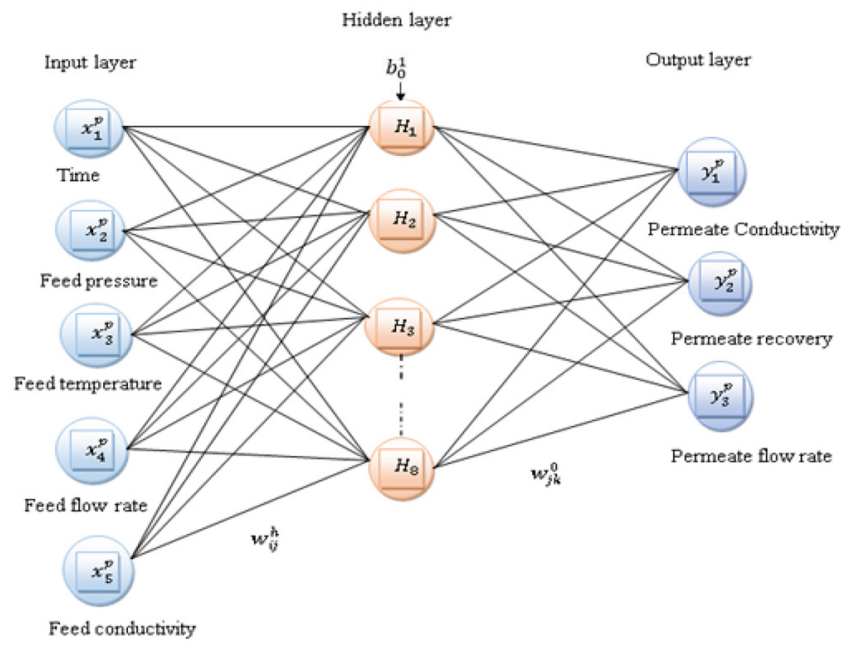

Fig. 2. Schematic diagram of an artificial neural network model.

\subsubsection{Multi-Linear Regression Model (MLR)}

The MLR is a simple extension of linear regression, but instead of relating one dependent outcome variable $\mathrm{y}$ to one independent variable $\mathrm{x}$, [36, 37].

The MLR model for an outcome variable $\mathrm{Y}$ as a function or predictor variables $\mathrm{x}_{1}, \mathrm{x}_{2}$, and so forth is as follows:

$$
\text { output }=x_{0}+\sum_{i=1}^{n} x_{i} d_{i}
$$

Where $x_{0}$ is regression constant, $a_{0}$ is a constant (intercept) and $x_{i}$ the coeffcient of predictorsin linear regression model. MLR calculations were performed using STATISTICA v. 8.0 (Stat Soft,
Inc.) software.

\subsection{Statistical Performance Evaluation Criteria}

In order to evaluate the quality of the prediction of ANN and MLR models, there are set of evaluation criteria such as the coefficient of correlation R, mean absolute error (MAE) and root mean square error (RMSE) [38] for the prediction of permeate conductivity, recovery and permeate flow rate, also the average absolute relative deviation $A A R D[35,39]$. The equations are expressed in below:

$$
\begin{gathered}
R=\frac{\sum_{i}\left(y_{\text {exp }}-\overline{y_{\text {exp }}}\right)\left(y_{\text {cal }}-\overline{y_{\text {cal }}}\right)}{\sqrt{\sum_{i}\left(y_{\text {exp }}-\overline{y_{\text {exp }}}\right)^{2}} \sqrt{\sum_{i}\left(y_{\text {cal }}-\overline{y_{\text {cal }}}\right)^{2}}} \\
R M S E=\sqrt{\frac{1}{N} \sum_{i=1}^{N}\left(y^{\text {exp }}-y^{c a l}\right)^{2}} \\
M A E=\frac{1}{N} \sum_{i=1}^{N}\left|\left(Y_{\text {exp }}-Y_{\text {cal }}\right)\right| \\
A A R D=\frac{1}{N} \sum_{i=1}^{N}\left|\frac{y^{\text {exp }}-y^{c a l}}{y^{\text {exp }}}\right|
\end{gathered}
$$

Here $N$ is the number of experiments, $y_{\exp }$ is the experimental value for each parameter, $\mathrm{y}_{\text {cal }}$ is respectively the predicted value of the $i^{\text {th }}$ experiment calculate by the model for each parameter. and are the arithmetic mean of experimental $\overline{y_{\exp }}$ and $\overline{y_{c a l}}$ are the arithmetic mean of experimental and calculated values.

In this current work, the artificial neural network was used due to their flexibility to conform to any type of data set and due to their success with various engineering problems [40-45]. Furthermore, the performance of ANN model was validated for extrapolated predictions and the model employed in the research provided the most accurate predictions compared to MLR method.

\section{Results and Discussion}

\subsection{Comparison of the ANN Model and MLR Model}

The results of the ANN model and MLR model were evaluated based on the comparison between the model outputs and the experimental data using coefficient of correlation $\mathrm{R}$ as shown in Fig. 3. The statistical parameters obtained from the model fits are also summarized in Table 2 .

The ANN models resulted in good agreements with the plant data compared to MLR models. Through the analysis of Table 2 , the model statistical parameters for the prediction results obtained from using Levenberg-Marquadt program written on MATLAB software. For permeate conductivity $R=$ [0.98 (ANN), 0.622 (MLR)], for permeate recovery $R=$ [0.964 (ANN), $0.572(\mathrm{MLR})]$ and for permeate flow rate $R=$ [0.942 (ANN), 0.679 (MLR)].

Through the studies conducted by both madaeni [28] and Cabrera et al. [29] which predicted the permeate flow rate and permeate conductivity, and by comparing the results obtained, it was confirmed that ANN could modelling the both target with accurately.

According to Garg et al. [26] and salami et al. [50] and further 
Table 2. Linear Regression Vectors [linear equation: $y^{\text {predict }}=\alpha y^{\exp }+\beta$, with $\alpha=$ slope, $\beta=y$ intercept], R, RMSE, MAE and AARD

\begin{tabular}{lccccccc}
\hline & & $\alpha$ & $\beta$ & $\boldsymbol{R}$ & $\boldsymbol{R M S E}$ & $\boldsymbol{M A E}$ & $\boldsymbol{A A R D}$ \\
\hline \multirow{2}{*}{ Permeate Conductivity $(\mu \mathrm{S} / \mathrm{cm})$} & ANN & 1.0061 & -6.9152 & 0.9691 & 11.7 & 0.6934 & 0.4571 \\
& MLR & 1.000 & 0.002 & 0.622 & 24.100 & 29.171 & 1.531 \\
\hline \multirow{2}{*}{ Permeate Flow rate $\left(\mathrm{m}^{3} / \mathrm{h}\right)$} & ANN & 1.0065 & -0.0092 & 0.9422 & 0.0132 & 0.0108 & 0.4583 \\
& MLR & 1.00 & $2.3310-6$ & 0.679 & 0.021 & 0.0246 & 1.0585 \\
\hline \multirow{2}{*}{ Permeate recovery $(\%)$} & ANN & 1.0062 & -0.2750 & 0.9636 & 0.2630 & 0.2202 & 0.2977 \\
& MLR & 1.000 & $-7.56010-5$ & 0.572 & 0.316 & 0.646 & 0.8842 \\
\hline
\end{tabular}
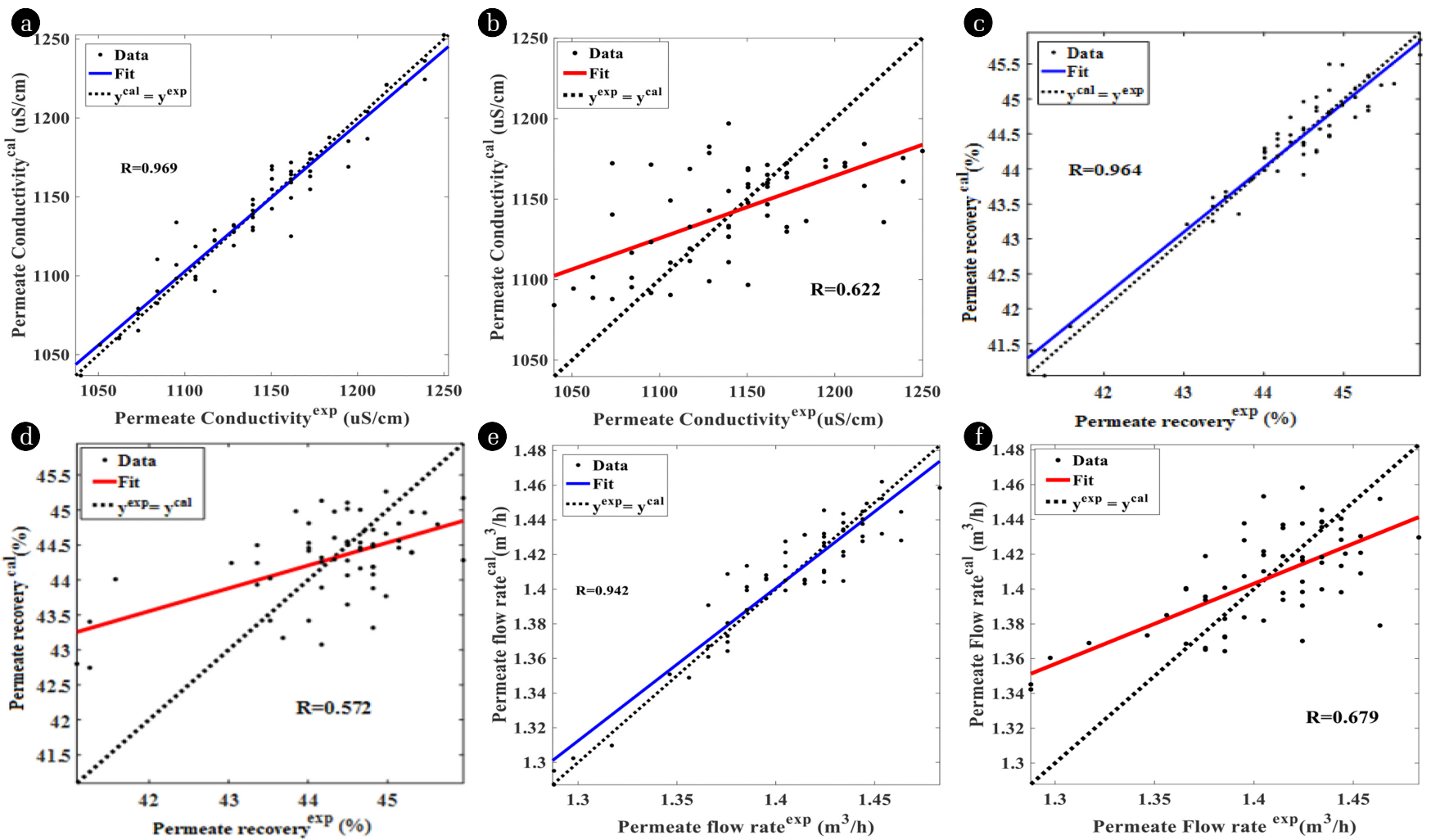

Fig. 3. Statistical analysis parameters of MLR and ANN models. (a), (c), (e) ANN (b), (d), (f) MLR.
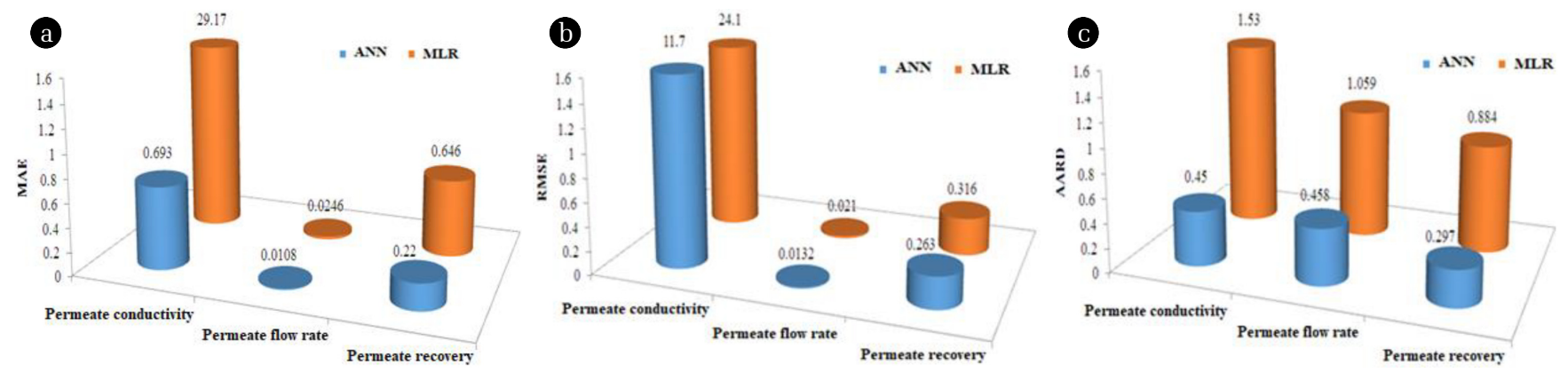

Fig. 4. Statistical analysis parameters of MLR and ANN models.

confirmation of the permeate recovery prediction of the performance membrane desalination process, the ANN model proposed in this study yielded satisfactory results that can be used as a model for controlling the desalination membrane filtration performance. In fact, the results show that ANN models were indicated high value of correlation coefficient compared to MLR models. Furthermore, Fig. 4 shows the different statistical parameters obtained for ANN and MLR models. It is observed that for permeate conductivity, permeate recovery and permeate flow rate the MAE, RMSE and AARD values considering more reasonable for ANN 
models and for MLR models, these statistical parameters are generally considered moderate. Since the neural network model shows good accuracy in predicting these parameters, it could be considerate that the ANN the best-simulated model and is suitable for prediction of seawater desalination performance hybrid process $\mathrm{NF} / \mathrm{RO}$ in the mean of improving the quality of the water produced and reduce water production costs.

\subsection{Mathematical Equations of MLR Developed Model}

The models obtained for the prediction of the permeate conductivity, permeate recovery, and permeate flow for the hybrid NF/RO process seawater desalination are linear models according to the subsequent equations:

$$
\begin{gathered}
\delta_{p}=-301.039-0.53 t+0.635 P+0.536 T+0.122 J_{A}+0.070 \delta_{A}(9) \\
y=111.49+0.177 t+0.195 P-0.28 T-0.36 J_{A}-0.30 \delta_{A} \quad(10) \\
\boldsymbol{Q}_{p}=2.68+0.400 t-0.0666 P+0.1792 T+0.205 J_{A}+0.129 \delta_{A}(11)
\end{gathered}
$$

\subsection{Mathematical Equations of ANN Developed Model}

The proposed neural network model successfully predicts the key NF/RO performance parameters i.e., Permeate conductivity, recovery and flow rate for the simulated system desalination. The real prediction power of the ANN model is observed when the simulated and experimental values of the predicted parameters are established as a mathematical function. By integrating all the inputs $x_{i}$ by the mathematical formula is presented as follow: Knowing that $f_{h}$ is the Tangent sigmoid transfer function used in hidden layer:

$$
\begin{aligned}
& Z_{j}=f_{h}\left[\sum_{i=1}^{5} w_{j i} x_{i}+b_{j}^{h}\right]=\frac{\exp \left(\sum_{i=1}^{5} w_{j i} x_{i}+b_{j}^{h}\right)-\exp \left(-\sum_{i=1}^{5} w_{j i} x_{i}+b_{j}^{h}\right)}{\exp \left(\sum_{i=1}^{5} w_{j i} x_{i}+b_{j}^{h}\right)+\exp \left(-\sum_{i=1}^{5} w_{j i} x_{i}+b_{j}^{h}\right)} \\
& j=1,2, \ldots \ldots 8
\end{aligned}
$$

The output $\mathrm{H}$, where $f_{0}$ is the pure linear transfer function used in output layer presented as Eq. (18):

$$
\mathrm{H}=f_{0}\left[\sum_{i=1}^{8} w_{j i}^{H} Z_{i}+b_{3}^{0}\right]
$$

Combining Eq. (18) and Eq. (19) for obtain the relation formula of the output parameters of the ANN as follow:

$$
\delta_{p}, Q_{p}, y=\sum_{i=1}^{8} w_{j i}^{H}\left(\frac{\exp \left(\sum_{i=1}^{5} w_{j i} x_{i}+b_{j}^{h}\right)-\exp \left(-\sum_{i=1}^{5} w_{j i} x_{i}+b_{j}^{h}\right)}{\exp \left(\sum_{i=1}^{5} w_{j i} x_{i}+b_{j}^{h}\right)+\exp \left(-\sum_{i=1}^{5} w_{j i} x_{i}+b_{j}^{h}\right)}\right)+b_{3}^{0}
$$

The mathematical equation of the predicted permeate conductivity $\left(\delta_{p}\right)$, permeate flow rate $\left(Q_{p}\right)$ and permeate recovery $(y)$ is given by the Eq. (14).

Where $j$ is the number of neurons in the hidden layer $(j=8), i$ is the number of neurons in the input layer $(i=5), w^{I}\left(w_{(j, i)}^{H}\right)$ and $b_{1}^{H}$ are weights and bias between input and hidden layer, $\mathrm{w}^{\mathrm{H}}\left(w_{(, j, j)}^{0}\right)$ and $b_{3}^{0}$ are weights and bias between hidden and output layer, $l$ is the number of neurons in output layer $(l=3)$.

The model established from ANN to predict the performance of the NF /RO hybrid seawater treatment, including important relevant features that can be easily applied in the optimization of desalination systems.

\subsection{Sensitivity Analysis}

To assess the performance of $\mathrm{NF} / \mathrm{RO}$ desalination unit the effect of the individual inputs on the outputs of the system can be studied in ANN. Weights method was employed in this study. The Weights method was proposed initially by Garson [51] and repeated by Goh [52] as a procedure for partitioning the connection weights to determine the relative importance $\left(R_{I}\right)$ of the various inputs. The method essentially involves partitioning the hidden-output connection weights of each hidden neuron into components associated with each input neuron. The relative importance (\%) calculated based on Garson equation [53]:

$$
R_{I j}=\frac{\sum_{m=1}^{N_{h}}\left(\left(\frac{\left|w_{j m}^{i h}\right|}{\sum_{k=1}^{N_{i}}\left|w_{k m}^{i h}\right|}\right) \times\left|W_{m n}^{h 0}\right|\right)}{\sum_{k=1}^{N_{i}}\left\{\sum_{m=1}^{N_{h}}\left(\left(\frac{\left|W_{k m}^{i h}\right|}{\sum_{k=1}^{N_{i}}\left|w_{k m}^{i h}\right|}\right) \times\left|W_{m n}^{h 0}\right|\right\}\right.}
$$

where $I_{j}$ is the relative importance of the $j^{\text {th }}$ input variable on output variable; $N_{i}$ and $N_{h}$ are the number of input and hidden neurons, respectively; $W$ are connection weights; the superscripts $i, h$, and $o$ refer to input, hidden and output layers, respectively; and subscripts $k, m$, and $n$ refer to input, hidden and output neurons, respectively [53]. The numerator of the Eq. (15) describes the sum of the absolute products of the weights for each input.

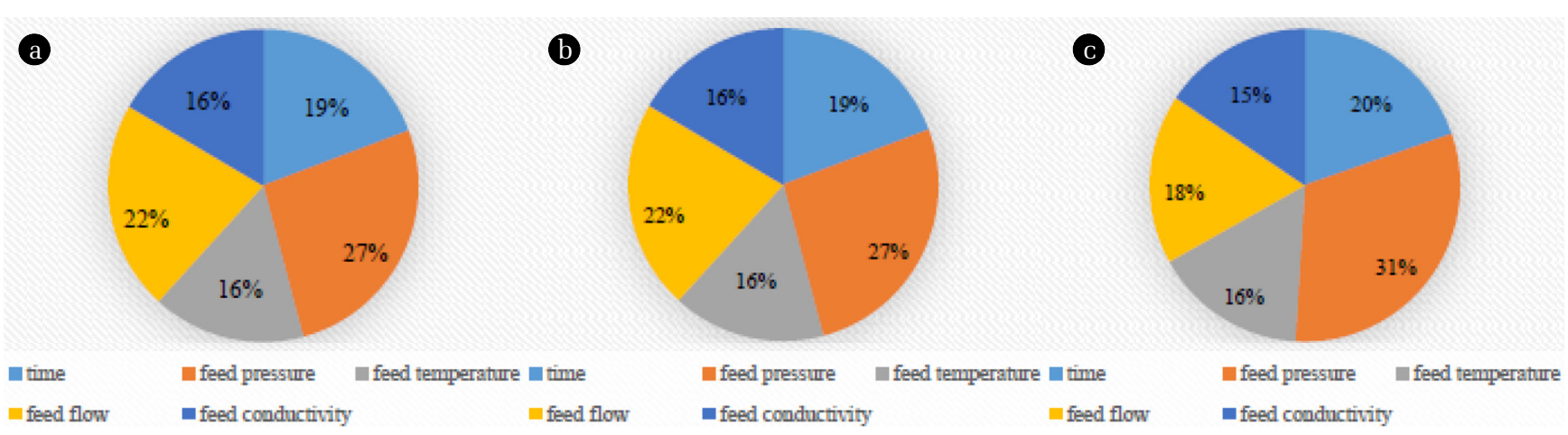

Fig. 5. The importance percentage distribution of each inputs variable on (a) permeate conductivity (b) permeate recovery and (c) permeate flow. 
The relative importance of various variables calculated by Eq. (15) is shown in Fig. 5. As can be seen, all the variables have strong effects on the permeate flow rate, conductivity and water recovery values. Therefore, it can be observed that the highest contribution was obtained with feed pressure (P) about (27\%) on all the outputs. Both permeate conductivity and permeate water recovery affected strongly by feed flow (22\%).Time and conductivity and temperature have the same influence on all the outputs values about (16\%). That explains that the selected inputs parameters have a strong effect on the outputs and a strong significance in the performance of hybrid NF/RO seawater desalination unit.

\section{Conclusions}

The objective of the present paper was to develop an ANN model able to predict the performance of hybrid NF/RO seawater desalination unit considering the most important inputs variables, namely the feed temperature, the feed pressure, the feed flow rate and feed conductivity. The NN was used for prediction permeate conductivity, permeate flow rate and permeate recovery with the aim of optimization of NF/RO process. Comparison of neuronal network and MLR, revealed that ANN models determination coefficient $\mathrm{R}$ for the three outputs is higher than obtained by MLR models as well as satisfactory statistical parameters. However, according to the prediction results, the ANN model was found to have a successful ability to predict The NF/RO process performance seawater desalination compared to the MLR model. In conclusion, it is important to study the system parameters in order to enhance the $\mathrm{NF} / \mathrm{RO}$ hybrid process and optimize the seawater desalination operation.

In the future works, the models presented in this paper will be used for developing optimization algorithms able to perform optimal designs of a solar-powered $\mathrm{NF} / \mathrm{RO}$ seawater desalination process facility to be integrated into the plant.

\section{Nomenclature}

$t$ : Time

$p:$ pressure

$T$ : temperature

$J_{f}:$ Feed flow rate

$\delta_{f}:$ Feed conductivity

$\delta_{p}$ : Permeate conductivity

$J_{p}:$ Permeate flow rate

$y$ : permeate recovery

$\mathrm{h}$
$\mathrm{Kg} / \mathrm{cm}^{2}$
${ }^{\circ} \mathrm{C}$
$\mathrm{m}^{3} / \mathrm{h}$
$\mu \mathrm{S} / \mathrm{cm}$
$\mu \mathrm{S} / \mathrm{cm}$
$\mathrm{m}^{3} / \mathrm{h}$
$\%$

\section{Acknowledgments}

The authors gratefully acknowledge the Algerian Ministry of Higher Education and Scientific Research (CNEPRU Projects Nos. J0102620110007 and J0102620140015) and Laboratory of Biomaterials and Transport Phenomena (LBMPT) of University Yahia Fares of Medea, Algeria.

\section{Author Contributions}

A.A. (Ph.D) conducted all the experiments and wrote the manuscript. S.B. (Ph.D) and S.H. (Professor) interpreted the results obtained and reviewed the article. L.M (Ph.D) realized modelling part and MATLAB programming. M.A. (Professor) revised the manuscript.

\section{Reference}

1. Choi Y, Lee Y, Shin K, Park Y, Lee S. Analysis of long-term performance of full-scale reverse osmosis desalination plant using artificial neural network and tree model. Environ. Eng. Res. 2020;25:763-770.

2. Rodríguez-Calvo A, Silva-CastroGA, Osorio F, López JG, Calvo C. Reverse osmosis seawater desalination: current status of membrane systems. Desalin. Water. Treat. 2015;56:849-861.

3. Lee E, Lee S, Hong S. A new approach to the characterization of reverse osmosis membrane by dynamic hysteresis. Desalin. Water. Treat. 2010;18:257-263.

4. Diem XV. Two stage nanofiltration seawater desalination system, United State Patent 7, 144, December. 2006;511-B2.

5. Basile A, Cassano A, Rastogi NK. (Eds.). Advances in Membrane technologies for water treatment-Materials, Processes and Applications. $1^{\text {st }}$ Edition. Woodhead Publishing; 2015.

6. Diawara CK. Nanofiltration Process Efficiency in Water Desalination. Sep. Purif. Rev. 2008;37:302-324.

7. Hilal N, Al-Zoubi H, Darwish NA, Mohamma AW, Arabi MA. A comprehensive review of nanofiltration membranes: Treatment, pretreatment, modelling, and atomic force microscopy. Desalination 2004;170:281-308.

8. Fritzmann C, Löwenberg J, Wintgens T, Melin T. State-of-the-art of reverse osmosis desalination. Desalination 2007;216:1-76.

9. Khawaji AD, Kutubkhanah IK, Wie JM. Advances in seawater desalination technologies. Desalination 2008;221:47-69.

10. Bellona C, Drewes JE. Role of membrane surface charge and solute physicochemical properties in the rejection of organic acids by NF membranes. J. Membrane. Sci. 2005;249:227-234.

11. M'nif A, Bouguecha S, Hamrouni B, Dhahbi M. Coupling of membrane processes for brackish water desalination. Desalination 2007;203:331-336.

12. Hassan AM, Farooque AM, Jamaluddin ATM, et al. Optimization of NF Pretreatment of Feed to Seawater Desalination Plants. In: IDA World Congress on Desalination Water Reuse; 29 Aug-3 Sept 1999; San Diego, USA.

13. Hassan AM, Al-Sofi MA, Al-Amoudi A, et al. A Nanofiltration (NF) Membrane Pretreatment of SWRO Feed and MSF Make-up. In: IDA World Congress on Desalination and Water Reuse : October 6-9 1997; Madrid, Spain. 1997.

14. Hassan AM, Al-Sofi MA, Al-Amoudi A, et al. A new approach to membrane and thermal seawater desalination processes using nanofiltration membrane (part 1). Desalination 1998;118:35-51.

15. Hassan AM, Al-Sofi MAK, Farooque AM, et al. A nano filtration (NF) membrane pretreatment of SWRO feed and MSF make-up (part 1). In: 4th WSTA Conference: 13-17 Feb 1999; Bahrain. p. 13-17. 
16. Drioll E, Criscuoli A, Curcio E. Integrated membrane operations for seawater desalination. Desalination 2002;147:77-81.

17. Drioli E, Curcio E, DiProfio G, et al. Integrating membrane contactors technology and pressure-driven membrane operations for seawater desalination: energy, Exergy and Costs Analysis. Chem. Eng. Res. Des. 2006;84:209-220.

18. Turek M, Chorążewska M. Nanofiltration process for seawater desalination-salt production integrated system. Desalin. Water. Treat. 2004;7:178-181.

19. AlTaee A, Sharif AO. Alternative design to dual stage NF seawater desalination using high rejection brackish water membranes. Desalination 2011;273:391-397.

20. Kaya C, Sert G, Kabay N, Arda M, Yüksel M, Egemen Ö. Pre-treatment of nanofiltration (NF) in seawater Desalination-Preliminary integrated membrane tests in Urla, Turkey. Desalination 2015;369:10-17.

21. Kaya C, Jarma YA, Guler E, Kabay N, Arda M, Yükse M. Seawater Desalination by using Nanofiltration (NF) and Brackish Water Reverse Osmosis (BWRO) Membranes in Sequential Mode of Operation. J. Membrane. Sci. Res. 2020;6:40-46.

22. Singh R, Tembrock J. Effectively control reverse osmosis systems, Chem. Eng. Prog. 1999;95:57-64

23. Suykens JA, Vandewalle JP, De Moor BLR. Artificial neural networks for modelling and control of non-linear systems. 1st ed. New York; Springer. 1996.

24. El-Hawary ME. Artificial neural networks and possible applications to desalination. Desalination 1993; 92:125-147.

25. Abbas A, Al-Bastaki N. Modeling of an RO water desalination unit using neural networks, Chem. Eng. J. 2005;114:1-3.

26. Garg MC, Joshi H. A new approach for optimization of small-scale RO membrane using artificial groundwater. Environ. Technol. 2014;35:2988-2999.

27. Aish AM, Zaqoot HA, Abdeljawad SM. Artificial neural network approach for predicting reverse osmosis desalination plants performance in the Gaza Strip. Desalination 2015;367:240-247.

28. Madaeni SS, Shiri M, Kurdian AR. Modeling, optimization, and control of reverse osmosis water treatment in kazeroon power plant using neural network. Chem. Eng. Commun. 2015;202:6-14.

29. Cabrera U, Bogdanov D, Breyer C. Chapter 8-Desalination costs using renewable energy technologies. In: Veera Gnaneswar Gude ed. Renewable Energy Powered Desalination Handbook. Woburn, MA: Butterworth-Heinemann; 2018. p. 287-329.

30. Hamed OA, Hassan AM, Al-Shail, Farooque KMA. Performance analysis of a trihybrid NF/RO/MSF desalination plant. Desalin. Water. Treat. 2009;1:215-222.

31. Bhagat P. An introduction to neural nets. Chem. Eng. Prog. 1990;86:55-60

32. Malinov S, Sha W. Software products for modelling and simulation in materials science. Comp. Mater. Sci. 2003;28:179-198.

33. Esteban LG, Fernández FG, De Palacios P. Prediction of plywood bonding quality using an artificial neural network. Holzforschung 2011;65:209-214.

34. Si-Moussa C, Hanini S, Derriche R, Bouhedda M, Bouzidi A. Prediciton of high-pressure vapor liquid equilibrium of six binary systems, carbon dioxide with six esters, using an artificial neural network model. Brazilian. J. Chem. Eng. 2008;25:183-199.
35. Adda A, Hanini S, Abbas M, Sediri M. Novel adsorption model of filtration process in polycarbonate track-etched membrane: Comparative study. Environ. Eng. Res. 2019;25:479-487.

36. Neil R, malheiser S. Data Literacy: How to Make Your Experiments Robust and Reproducible. In: 1st Ed. $3^{\text {rd }}$ chapter. New York: Academic Press; 2017.

37. Sinnakaudan SK, Ghani AA, Ahmad MSS, Zakaria NA. Multiple Linear Regression Model for Total Bed Material Load Prediction. J. Hydraul. Eng. 2006;132:521-528.

38. Mohamedi B, Hanini S, Ararem A, Mellel N. Simulation of nucleate boiling under ANSYS-FLUENT code by using RPI model coupling with artificial neural networks. Nuclear. Sci. Technol. 2015;26:40601-040601.

39. Hamadache M, Hanini S, Benkortbi O, Amrane A, Khaouane L, Si Moussa C. Artificial neural network-based equation to predict the toxicity of herbicides on rats. J. Chemometr. Intell. Lab. Syst. 2016;154:7-15.

40. Choi Y, Lee Y, Shin K, Park Y, Lee S. Analysis of long-term performance of full-scale reverse osmosis desalination plant using artificial neural network and tree model. Environ. Eng. Res. 2019;5:763-770.

41. Kaushal NG, Rahul K. Fixed bed utilization for the isolation of xylene vapor: Kinetics and optimization using response surface methodology and artificial neural network. Environ. Eng. Res. 2021;26:200-105

42. Muhammad Y, Seung HL. Experimental and neural network modeling of micellar enhanced ultrafiltration for arsenic removal from aqueous solution. Environ. Eng. Res. 2021;26:190-261.

43. Braimah, MN. Comparison of Optimization of Exergy Efficiency of a Crude Distillation Unit Using Artificial Neural Network (ANN) and Response Surface Methods (RSM). J. Eng. Res. Rep. 2020;1-14.

44. Erkaymaz O, Ozer M. Impact of small-world network topology on the conventional artificial neural network for the diagnosis of diabetes. Chaos. Soliton. Fract. 2016;83:178-185.

45. Morfidis K, Kostinakis K. Seismic parameters combinations for the optimum prediction of the damage state of $\mathrm{R} / \mathrm{C}$ buildings using neural networks. Adv. Eng. Soft. 2017;106:1-16.

46. Adeloye AJ. Multiple Linear Regression and Artificial Neural Network Models for Generalized Reservoir Storage-YieldReliability Function for Reservoir Planning. J. Hydraul. Eng. 2009;14:731-738

47. Heuvelmans G, Muys B, Feyen J. Regionalisation of the Parameters of a Hydrological Model: Comparison of Linear Regression Models with Artificial Neural Nets. J. Hydraul. Eng. 2006;319:245-265.

48. Thambavani, DS, Mageswari, TSRU. Application of multivariate linear regression and neural network in the assessment of groundwater quality. Int. J. Chem. Technol. Res. 2005;8:12821289.

49. Sahoo S, Jha, MK. Groundwater-Level Prediction Using Multiple Linear Regression and Artificial Neural Network Techniques: A Comparative Assessment. Hydraul. J. 2013;2:1865-1887.

50. Salami ES, Ehetshami M, Karimi-Jashni A, Salari M, Nikbakht SS, Ehteshami A. A mathematical method and artificial neural network modeling to simulate osmosis membrane's performance. Model. Earth. Syst. Environ. 2016;2:207. 
51. Garson GD. Interpreting neural network connection weights. AI Expet. 1991;6:47-51.

52. Goh ATC. Back-propagation neural networks for modeling complex systems. Artif. Intell. Eng. 1995;9:143-151.
53. Laidi M, Hanini S. Optimal solar COP prediction of a solar-assisted adsorption refrigeration system working with activated carbon/methanol as working pairs using direct and inverse artificial neural network. Int. J. Refrig. 2013;36:247-257. 